\title{
Factors influencing IT-Business Strategic Alignment and Sustainable Competitive Advantage: A Structural Equation Modelling Approach
}

\author{
Dmaithan Abdelkarim Almajali and Zulkhairi Md Dahalin \\ College of Arts \& Sciences, Universiti Utara Malaysia, Malaysia
}

\begin{abstract}
Preceding research attributed the lack of direct causal impact of Information Technology (IT) on firm's sustainable competitive advantage. Numerous missing links include antecedents of the ITbusiness strategic alignment (also known as strategic alignment) and the sustainable competitive advantage. Furthermore, reviewers of recent literature have called for more research into the factors that affect strategic alignment, and the linkage between alignment and sustainable competitive advantage. In this paper, we develop and empirically test specific forms of management structures and processes which are required to drive strategic alignment. Further, we propose a causal-chain model to examine the impacts of six antecedents on strategic alignment. The data are collected from over 172 Jordanian public shareholding firms. Using structural equation modeling for data analysis, this study finds general support for the hypotheses that leadership, values and belief, IT managerial resources, service quality, and IT implementation successes significantly impact IT-business strategic alignment. However, no relationship is found between structure and process and strategic alignment.
\end{abstract}

Keywords: Information Technology, IT-Business Strategic Alignment, sustainable competitive advantage.

\section{Introduction}

Over the past decade, information technology has progressed simultaneously with the rapid global development, and emerged as a very important part of most business firms. For organizations to stay competitive in a dynamic business environment, they have to understand how to manage IT strategically.

About IT and productivity, one of the most widely cited quote by Solow (1987) is, "we see computers age everywhere except in the productivity statistics". This phenomenon is commonly known as the 'Productivity Paradox', which states that IT investments do not affect productivity growth. Indeed, earlier studies in 1980s found no significant, direct relationship between IT investment and productivity at the level of firms, industries, and the economy (Strassmann, 1990). However, later research has generated mixed and inconclusive findings. In response to this, economists, MIS researchers and management scientists have encouraged more research at a finer-level of analysis of the causal links between IT and productivity.

In the field of IS, the focus is on the identification of the missing links as part of the causal chain between IT and firm performance (Chan et al., 2006; Kearns \& Lederer, 2001; Masa'deh et al., 2010). Hu and

Copyright(C2011 Dmaithan Abdelkarim Almajali and Zulkhairi Md Dahalin.This is an open access article distributed under the Creative Commons Attribution License unported 3.0, which permits unrestricted use, distribution, and reproduction in any medium, provided that original work is properly cited. Contact author: Dmaithan Abdelkarim e-maill: admethan2004@yahoo.com 
Huang (2005) argue that the way in which business strategy aligns with IT strategy in the real world still remains unanswered. Mahmood (1993) states that strategic managers clearly need a better understanding of the impact of IT investment on organizational strategic and economic performance. This view is reiterated by many IS researchers that IT-business alignment can help organizations improve the positive impact of IT on their performance (Croteau et al., 2001; Henderson \& Venkatraman, 1993). Despite a growing body of research (Brown \& Magill, 1994 ), recent scholars (Chan \& Reich, 2007; Johnson \& Lederer, 2010; Raymond \& Croteau, 2009) have continuously called for further investigation for examining the factors that affect ITbusiness alignment; and the coupling processes from alignment to enhance sustainable competitive advantage. Indeed, since little research has been conducted in this area, and in an effort to respond to several calls from well-known scholars on this issue, we present a causal model for quantitative testing of the impacts of six antecedents that could lead to strategic alignment.

The rest of this paper is organized as follows. Next section discusses the theoretical background of this research. Then, in line with the research framework of this study, propositions are developed on the direct impact of the antecedent factors on strategic alignment. The following sections describe the research design, the results, and the implications for both research and practice. The paper ends with a number of conclusions and recommendations.

\section{Theoretical Background}

Numerous articles have been written about how IT affects organizational performance (Dedrick, 2003). A major concern is how to assess the IT- related business value and organizational impacts. Broadly, there are two main approaches. The first approach examines the direct and multiple linkages between IT investment and organizational performance across economy, industry, and firm. The second approach examines the indirect linkages between IT investment and organizational performance through identifying important mediating factor. These two approaches often lead to contradicting results. Some research shows no significant correlation whereas others indicate a positive relationship between IT investment and business performance (Henderson \& Venkatraman, 1993).

The challenge is not only to identify the crucial factors that affect business performance but also to build a credible causal chain between IT and business performance. Most of the MIS research has started with IT-business alignment as an important missing link between IT and organizational performance (Shannak et al., 2010).

\section{IT-Business Strategic Alignment}

Alignment of IT or IS strategy with business strategy has been ranked as one of the most important issues faced by business and IT executives (Almajali \& Dahalin, 2010b). Alignment has been defined as the extent to which the IT mission, objectives and plans support and are supported by their business counterparts (Reich \& Benbasat, 2000). Further, IT-business alignment concerns the degree of correspondence of an organization's IT strategy and IT infrastructure with the organization's strategic business objectives and infrastructure. Since the late 1980s, alignment has been an important concern to the business community as it not only helps firms realize the potential benefits from investments in IT (Tallon et al., 2000), but also enhances business performance through aligning the organizational and technological infrastructures (Croteau et al., 2001). However, despite various types of alignment, our main focus here is on investigating the impact of several strategic alignment antecedents on strategic alignment. We hope this study will provide better insights into 
the conditions of alignment in terms of the antecedent variables. Next section discusses our research framework.

\section{Sustainable Competitive Advantage}

Porter's (1985) book titled 'Competitive Advantage' propelled the concept of competitive advantage into popular business vernacular. Porter did not articulate the definition of the concept but explained that a competitive advantage refers to organizational factors that enable a firm to outperform its competitors. As such, Porter argued that sustaining competitive advantage should be the central purpose of an organization's competitive strategy and that value creation means attaining the sustaining competitive advantage. As Collis and Montgomery (1995) explained, competitive advantage, whatever its source, ultimately can be attributed to the ownership of a valuable resource that enables the company to perform activities better or more cheaply than its Competitors. To be sustainable, a competitive advantage should be difficult to imitate or substitute (Barney, 1991). Boar (1994), for example, states: "In response to ever growing worldwide competition, the business needs to use IT to build, sustain and extend competitive advantage. "Most major strategic thrusts require the crafted use of IT to succeed" (p. 16).

\section{Research Propositions}

In this section, we formulate our research propositions based on the review of existing literature of strategic alignment. The model of this study comprises main effects of six antecedents (i.e., leadership, structure and process, service quality, value and belief, IT managerial resource, and IT implementation success) on strategic alignment and its effect on sustainable competitive advantage.

\section{Leadership}

Research on strategic alignment underlines the importance of reciprocal relationship between business and IT executives to facilitate synergy between business and IT. Lederer and Mendelow (1987 )found that business managers seldom assist IS managers in formulating their plans. They asserted that two-way communication between business and IT executives is essential if business and IT plans are to be coordinated. Earl and Feeny (1994) found that the CIO's role and actions are vital to ensure that IT is positioned for strategic advantage. This leads to the following proposition:

- Proposition 1: The stronger leadership between business and IT managers, the greater the manager's engagement in strategic alignment.

\section{Structure and Process}

Structures and processes are the mechanisms through which organisational activity takes place. Structures and processes are concerned with how the organisation organises for IT, including IS/IT strategy development, delivery of IT benefits, structures for service delivery, mechanisms for business and IT organisation to bring together (Peppard \& Ward, 1999). Further, inadequate or inappropriate structures and processes can severely impinge on the success of IT in an organisation. Traditionally structures in relation to IT have been devised around the concept of technology delivery with a reactive IT organization developing products (i.e., applications) in response to business requests or around what it thinks the business requires. To facilitate IT/business integration, appropriate structures and processes are necessary. Therfore, we formulate the following proposition: 
- Proposition 2: The stronger structure and process with the business plan and IT plan, the greater the manager's engagement in strategic alignment.

\section{Service Quality}

Over the last decade, the marketing and quality literature have devoted reams to the issue of service quality and delivery. Within the quality movement there are the notions of the 'internal customer' and 'service level agreements' which are often devised to set parameters around the expected relationship.

The development of IT outsourcing has also seen the development of legally enforceable agreements specifying the level of service, which the client can expect from the vendor. Previously, there has been some interest in applying the concept of service management and quality to IT (Pitt et al, 1995; Van Dyke et al, 1997), which can be characterized merely as a customer-supplier exchange. However, the traditional role of the IT organization as the developer and maintainer of IT systems has been usurped by a variety of factors and its function now includes a significant service component. IS research has tended to focus on products rather than service and only recently has this service aspect been addressed. Also, the customer is the ultimate arbiter of quality and no matter how good the service provider feels, it is the perception of the customer that is important in assessing its quality. This has led to our third proposition:

- Proposition 3: The higher level of service quality between the business and IT managers, the greater the manager's engagement in strategic alignment.

\section{Values and Beliefs}

Values and beliefs can significantly shape how attitudes develop and hence behaviour and practices. These beliefs are shaped throughout one's career based on the experiences which one has with IT. For instance, inadequate structures and processes can impinge on the effective delivery of IT services even if there are congruent values and beliefs between the IT organisation and the rest of the business. Furthermore, the importance of values and beliefs to strategic alignment was also been acknowledged. Luftman et al., (1999) assured that values and beliefs will improve strategic alignment. Henderson and Venkatraman (1999) mentioned that values and beliefs affect the decision making ability of partners. Hence, this research proposed the following:

- Proposition 4: The stronger values and belief in the business plan and IT plan, the greater the manager's engagement in strategic alignment.

\section{IT Managerial Resource}

This factor concerns the level of mutuality in knowledge sharing and transfer. Chan et al., (2006) argued that reciprocal exchanges of business and IT knowledge between business and IT executives (Tallon, 2000) not only improve shared understanding but also promote common vision. Therefore, we formulate the following propositions:

- Proposition 5: The higher level of IT managerial resource between business and IT managers, the greater the manager's engagement in strategic alignment.

\section{IT Implementation Success}

Successful history of IT unit gives reliability to the IT unit and creates complimentary perceptions of IT in top management (Chan et al., 2006). Also, it gave essential determinant to the involvement of business managers in the planning process. The assurance of top management in the IT department for efficient and reliable services are found to be important critical success factors for aligning IS plans with business plans (Luftman et al.,1999). This has led to our sixth proposition: 
- Proposition 6: The higher level of IT implementation success between business and IT managers, the greater the manager's engagement in strategic alignment.

\section{Strategic Alignment and Sustainable Competitive Advantage}

In this study the researcher will hypothesize the relationship between strategic alignment and sustainable competitive advantage. This has led to our seventh proposition:

- Proposition 7: Firms that pursue strategic alignment will enhance their sustainable competitive advantage.

\section{Research Methods}

\section{Pilot Test and Data Collection}

Three Jordanian IT managers and two MIS academic professors participated in a pilot test. The researcher selected them based on their experience in the industry in order to get insightful information from the interview. They completed the survey in the presence of the first author. Then, they commented on the contents, length, and overall appearance of the questionnaire. Changes and modifications were made to the survey. Further, in order to ensure adequacy of response, a cover letter accompany each questionnaire to emphasize to respondents the importance of their participation. The researchers have chosen the country of Jordan to carry out the data collection since scholars Chan et al., (2006) called for such research in different cultures; and as this may open the gate to further research opportunities. Data for this research was obtained from IT managers of Jordanian public shareholding firms. The research population consists of all Jordanian banking, insurance, services, and manufacture companies that have a registered website, and which engage in business and IT activities. In the absence of any official lists, various government databases were reviewed; according to the Amman Stock
Exchange, and the Jordanian Securities Depository Center, the total number of companies stood at 200. A total of 172 managers returned the survey with high response rate of $86 \%$.

\section{Measures}

We developed a field survey for IT managers. All the research constructs were measured using closed-end seven-point Likert-scale items, with scales ranging from 1 = "strongly disagree" through $4=$ "neither agree nor disagree" to 7 = "strongly agree". Business and IT managers leadership variable was measured using six items which were drawn from (Ward \& Griffiths, 1996). Structure and process mechanism was measured using six items which were adapted from (Ward, \& Peppard 1996). Service quality variable was measured using five items which were drawn from Pitt et al. (1995). Values and beliefs were measured using six items, which were drawn from Grindley (1992). IT managerial resource was measured using four items, which were adapted from Nelson and Cooprider (1996). IT implementation success was measured using five items, which were adapted from Sabherwal and Kirs (1994). Strategic alignment was measured using six items which were drawn from Pierce (2002). Sustainable competitive advantage was measured using six items which were drawn from Al majali and Dahalin (2010a) and DeVilliers (2006). All the adaptations of these items were done to comply with the Jordanian context and validated during the pretest.

\section{Data Analysis and Results}

In order to examine whether the antecedents discussed above could impact IT-business strategic alignment in Jordanian public shareholding firms, a number of statistical tests were carried out. Indeed, the relationship between six strategic alignment antecedents and strategic alignment and sustainable competitive advantage were tested empirically using Structural Equation Modeling (SEM) techniques using the AMOS 
(Analysis of Moment Structures) software package version 6 . Table 1 in the appendices displays different types of goodness of fit indices in assessing our initial specified model. It shows that the research constructs fits the data moderately according to the absolute, incremental, and parsimonious model fit measures, comprising chi-square per degree of freedom ratio $\left(x^{2} / \mathrm{df}\right)$, Incremental Fit Index (IFI), Tucker-Lewis Index (TLI), Comparative Fit Index (CFI), and Root Mean Square Error of Approximation (RMSEA).

Further, we examined the standardized regression weights for the research's indicators and found that some indicators had a low loading towards the latent variables. In particular $(\mathrm{SP} 1=0.484, \mathrm{SQ} 3=$ $0.391, \mathrm{SQ5}=0.476, \mathrm{MR} 1=0.438, \mathrm{MR} 3=$ 0.451 , IS5 $=0.419$ ). Moreover, since all of these items did not meet the minimum recommended value of factor loadings of 0.50 (Newkirk \& Lederer, 2006), and because the initial fit indices were moderate for the sample data, they were all removed and excluded from further analysis. Consequently, the measurement model was modified and showed a better fit to the data (as shown in Table 1 in the appendices), although $x^{2} / \mathrm{df}$ and RMSEA did not change for the final model, the IFI $=0.81$, TLI $=0.80$, and CFI $=0.81$ indicated better fit to the data after deleting the low factor loading items (See table 1 in Appendix).

\section{Analysis of the Measurement Model}

After modifying the final measurement model for the eight constructs, the next stage is to assess them for unidimensionality, reliability, and validity.

\section{Unidimensionality}

Unidimensionality refers to the extent to which the research indicators form their latent variable. An examination of the unidimensionality of the research constructs is essential and an important prerequisite for establishing construct reliability and validity analysis (Chou et al., 2007). According to Byrne (2001), the evaluation of unidimensionality involves the assessment of the standardized factor loadings. The result shows strong evidence for the unidimensionality of the six constructs specified in the measurement model. All values of the different parameter estimates met the minimum recommended value of 0.50 (Newkirk \& Lederer, 2006).

\section{Reliability}

Reliability of the research scales have to be investigated to see the degree to which these scales indicate the research latent constructs. Cronbach alpha and composite reliability are seen as useful tests to measure construct reliability (Hair, 1998). The result indicates that all Cronbach alpha values for the six constructs exceeded the recommended value of 0.60, which according to Bagozzi and Yi (1988), indicates that the instrument is reliable. In addition, composite reliability values ranged from 0.80 to 0.97 , and were all greater than the recommended value of more than 0.60 (Bagozzi \& Yi, 1988) or greater than 0.70 as suggested by (Holmes-Smith, 2001). Consequently, according to the above two tests, all the research constructs in this study are considered reliable.

\section{Convergent and Discriminant Validity}

While convergent validity test is essential in the measurement model to determine if the indicators in a scale load together on a single construct, discriminant validity test is another important one to verify if the items that were developed to measure different constructs are certainly evaluating different constructs. As the result shows, all items were significant and had loadings more than 0.50 on their underlying constructs. Also, the standard errors for the items ranged from 0.043 to 0.361 and all the item loadings were more than twice their standard error. Indeed, discriminant validity was investigated using several tests. First, it could be examined in 
the measurement model by investigating the shared average variance extracted (AVE) by the latent constructs. Also, the correlations among the research constructs could be used to assess discriminant validity by examining if there is any extreme large correlations among them which imply that the model has a problem of discriminant validity. In addition, if the AVE for each construct exceeds the square correlation between that construct and any other constructs then discriminant validity is occurred (Fronell \& Larcker, 1981). As the result shows that all the constructs explained 50 percent or more of the variance and ranged from 0.82 to 0.92 which met the recommendation that AVE values should be at least 0.50 for each construct (Bagozzi \& Yi, 1988; HolmesSmith, 2001). However, the result shows discriminant validity was demonstrated since the AVE values were more than the squared correlations for each set of constructs. Therefore, the measures significantly discriminate between the constructs.

\section{Analysis of the Structural Model}

In order to test the structural model, it is essential to investigate the statistical significance of the standardized regression weights (i.e., $t$-value) of the research propositions at $0.10,0.01,0.05$, and 0.005 levels; and the coefficient of determination (Std. estim) for the research endogenous variables as well.

\section{Discussion and Implications}

This paper contributes to the strategic alignment literature by developing and empirically testing a causal chain model of alignment including the specification of six antecedents. Table 2 in the Appendix indicates the path coefficient and t-value of each proposed path. Consistent with Reich and Benbasat (2000), performing leadership by business and IT managers found to be positively but not strongly correlated with strategic alignment (P1). Indeed, Reich and Benbasat (2000) found that higher levels of formal communication between business and IT executives had a positive influence on short-term alignment.

Surprisingly, although great attention was made by several researchers regarding the correlation between structure and process mechanisms, there was no relationship between the association between such mechanisms and strategic alignment, indicating that (P2) was not empirically supported. In addition to structural issues, there are also processual mechanisms such as the involvement of business management in IS/IT strategy formulation which can impact the overall ownership of that strategy, alignment of the IS/IT strategy with business objectives, and responsibility for delivering business benefits. Yet our results are successed to show that firms performing better service quality could impact strategic alignment, showing that (P3) was empirically supported. Luftman et al., (2006) suggested that internet service providers should prioritize technology acquisitions and build appropriate infrastructures. All in all, more research is needed to clarify and explain the lack of support of (P2) bearing in mind that the research field based on the country of Jordan with different cultural context. A possible explanation is that Jordanian IT-managers are not aware of the importance of exploring such mechanisms. Thus, more research is required to understand how firms' structure and process activities affect strategic alignment, and further validate the study construct.

In line with previous studies, superior values and beliefs affected strategic alignment. Thus, (P4) was supported strongly. For instance, Bashein and Markus (1997) have introduced the concept of credibility in relation to IT specialists. They contend that expertise alone does not inspire trust and credibility, concluding that the successful IT specialists work on their trust worthiness while at the same time build good relationships with clients. To foster this credibility, IT specialists must, therefore, 
believe that trustworthiness and relationship building are necessary practices to engage in. Largely consistent with the literature (Basselier et al., 2003; Nelson \& Cooprider, 1996), IT managerial resources in terms of shared knowledge between business and IT managers was found to have a positive influence in strategic alignment. Therefore, (P5) was supported. Proposition 6 found that high level of IT implementation success experience a high level of strategic alignment. This result appears to provide support to the arguments and findings made by Rockart (1996) in which a successful IT track record improves of business relationships at all levels. Successful IT implementation may develop the relationship between IT and other functional areas (Boynton et al., 1994). Reich and Benbasat (2000) also found prior IS project success to assist short-term alignment. Thus, prior IS success is an important predictor of existing levels of alignment. The past suggestion and the credibility gaps cannot be ignored by managers but must be addressed as a high priority and must use new successes to improve its track record. The firm should facilitate the IS organization to better align itself, as a trusted partner, with the rest of the organization. Proposition 7 is to say the firms that pursuing strategic alignment has greater ability to enhance their sustainable competitive advantage. Therefore, (P7) was supported.

\section{Limitations and Conclusions}

There are some limitations of the study. The first limitation is that the proposed conceptual model is based on the crosssectional data from the Jordanian public shareholding firms. Therefore, longitudinal investigations are preferred for better implications of the strategic alignment. In addition, although the response rate of this study was sufficient for the condition of statistical analysis, the percentage of those who did not respond was still observable. In other words, even though the research results could be representative, it is reasonable to be watchful about its generalization. Thus, to increase statistical validity, further research should consider higher response rates. Also, the data and results reported in this paper were based on a single country, Jordan, and in turn are applicable specifically to the Jordanian context. Thus, this raises inquiries regarding the generalisability to other cultures and different contexts. Consequently, further research is needed with regard to several countries since this would help to advance understanding of the IT-business strategic alignment issue and the conditions and outcomes of achieving it from different nationwide origins in different contexts. All in all, although this paper investigated several propositions and offered empirical support for the acceptance and refusal of some of these propositions, more generalizations on the application of the theoretical premises that developed in building the research model will be needed to enrich and to build the alignment theory. This is to say, a more generalized research model that compensate the current research limitations by adding further impacting variables to the model and obtain a more representative sample from different sectors will be required.

\section{References}

Al majali, D., \& Dahalin, Z. (2010a). "ITBusiness Strategic Alignment Sustainable Competitive Advantage," Proceedings of the Conference of Organizational Innovation, Bangkok, Thailand.

Al majali, D. \& Dahalin, Z. (2010b). "Diagnosing the Gap in IT - Business Staregic Alignment: Aqualitative Analysi among Public Shareholding Firms in Jordan," Proceedings of the Conference on Innovation and Management, Penang, Malaysia.

Bagozzi, R. P. \& Yi, Y. (1988). "On the Evaluation of Structural Equation Models," Journal of The Academy of Marketing Science, 16(1). 74-94.

Barney, J. (1991), "Firm Resources and 
Sustained Competitive Advantage," Journal of Management, 17 (1). 99-120.

Bashein, B. J. \& Markus, M. L. (1997). "A Credibility Equation for IT Specialists," Sloan Management Review, 38, 4, 35-44.

Bassellier, G., Benbasat, I. \& Reich, B. H. (2003). "The Influence of Business Managers, IT Competence on Championing IT," Information Systems Research, 14(4). 317336.

Boar, B. H. (1994). "Logic and Information Technology Strategy: Separating Good sense from Nonsense," Journal of Systems Management, 45(5). 16-21.

Boynton, A. C., Zmud, R. W. \& Jacobs, G. C.(1994). "The Influence of IT Management Practice on IT Use in Large Organizations," MIS Quarterly, 18(3). 299-318.

Brown, C. V. \& Magill, S. L. (1994). "Alignment of the IS Functions with the Enterprise: Toward a Model of Antecedents," MIS Quarterly, 18(4). 371-403.

Byrne, B. (2001). "Structural Equation Modeling with Amos: Basic Concept, Applications, and Programming," Mahwah, New Jersey.

Chan, Y. E. \& Reich, B. H. (2007). "IT Alignment: What Have we Learned?," Journal of Information Technology, 22(4). 297-315.

Chan, Y. E., Sabherwal, R., \& Thatcher, J.B. (2006). "Antecedents and Outcomes of Strategic IS Alignment: An Empirical Investigation," IEEE Transactions on Engineering Management, 53(1). 27- 47.

Chou, T-C., Chang, P-L., Cheng, Y-P. \& Tasi, CT. (2007). "A Path Model Linking Organizational Knowledge Attributes, Information Processing Capabilities, and Perceived Usability," Information \& Management, 44, 408-417.
Collis, D. J. \& Montgomery, C. A. (1995). "Competing on Resources: Strategy in the 1990s," Harvard Business Review, 17 (1). 119128.

Croteau, A. M., Bergeron, F. \& Raymond, L. (2001). "Business Strategy and Technological Deployment: Fit and Performance," Information System and Management, 6 (4).

Dedrick, J., Gurbaxani, V. \& Kraemer, K. L. (2003). "Information Technology and Economic Performance: A Critical Review of the Empirical Evidence," ACM Computing Survey, 35(1) , 1- 28.

De Villiers, R . (2006). "Sources of Sustainable Competitive Advantage for Business Operating in Global Market Place," Unpublished doctoral Dissertation, University of Pretoria: The USA

Earl, M., \& Feeny, D. (1994). "Is your CIO Adding Value," Sloan Management Review, 35 (3). 11-20.

Fornell, C. \& Larcker, D. F. (1981). "Evaluating Structural Equation Models with Unobservable Variables and Measurement Error," Journal of Marketing Research, 18(1). 39-50.

Grindley, K. (1992). "Information Systems Issues Facing Senior Executives: The Culture Gap," The Journal of Strategic Information Systems, 1(2). 57-62.

Hair, J., Black, W., Babin, B., Anderson, R.\& Tatham, R. (1998). "Multivariate Data Analysis: Prentice hall Upper Saddle River," NJ.

Henderson, J. C. \& Venkatraman, N. (1993). "Strategic Alignment: Leveraging Information Technology for Transforming Organizations," IBM systems Journal, 32(1). 4-16. 
Henderson, J. C. \& Venkatraman, N. (1999). "Strategic Alignment: Leveraging Information Technology for Transforming Organizations," IBM Systems Journal, 38(2\&3). 472-484.

Holmes-Smith, P. (2001). "Introduction to Structural Equation Modelling Using LISREAL," Perth: ACSPRI-Winter Training Program.

Hu, Q. \& Huang, C. D. (2005). "Aligning IT with Firm Business Strategies Using the Balance Scorecard System," Proceedings of the 38th Hawaii International Conference on System Sciences.

Johnson, A. M. \& Lederer, A. L. (2010). "CEO/CIO Mutual Understanding, Strategic Alignment, and the Contribution of IS to the Organization," Information \& Management, 47(3). 138-149.

Kearns, G. S. \& Lederer, A. L. (2001). "Strategic IT-Alignment: A Model for Competitive Advantage," Proceedings of the 22nd ICIS, 1-12, Barcelona.

Lederer, A. L. \& Mendelow, A. L. (1989). "Coordination of Information Systems Plans with Business Plans," Journal of Management Information Systems, 6(2). 5-19.

Luftman, J. \& Brier, T. (1999). "Achieving and Sustaining Business-IT Alignment," California Management Review, 42(1). 109-122.

Luftman, J., Kempaiah, R. \& Nash, E. (2006). "Key Issues for IT Executives 2005," MIS Quarterly Executive, 5(2). 81-101.

Luftman, J., Papp, R. \& Brier, T. (1999). "Enablers and Inhibitors of Business-IT Alignment," Communications of the AIS, 1(11). 1-32.

Mahmood, M. A. (1993). "Associating Organizational Strategic Performance with Information Technology Investment: An Exploratory Research," European Journal of Information Systems, 2, 3, 185-200.
Masa'deh, R., Shannak, R., Obeidat, B ., Almajali, D. \& Dahalin, Z. (2010). "Investigating a Causal Model of IT-Business Partnership and Competitive Advantage," Proceeding of the 14th IBIMA conference on Innovation and Knowledge Management in Business: An Academic Perspective ,1250 1260.

Nelson, K. M. \& Cooprider, J. G. (1996). "The Contribution of Shared Knowledge to IS Group Performance," MIS Quarterly, 20(4). 409-432.

Newkirk, H. E. \& Lederer, A. L. (2006). "The Effectiveness of Strategic Information Systems Planning under Environmental Uncertainty," Information \& Management, 43, 481-501.

Peppard, J. \& Ward, J. (1999). "Mind the Gap: Diagnosing the Relationship Between the IT Organisation and the Rest of the Business," The Journal of Strategic Information Systems, 8(1). 29-60.

Pierce, A. C. (2002). "The Effect of Business and Information Technology Strategic Alignment on Information Technology Investment Returns and Corporate Performance," Unpublished Doctoral Dissertation, Nova Southeastern University. Retrieved May 15, 2010, from the UMI ProQuest Digital Dissertations database.

Pitt, L. F., Watson, R. T. \& Kavan, C. B. (1995). "Service Quality: A Measure of Information Systems Effectiveness," MIS Quarterly, 19(2). 173-187.

Porter, M. E. (1985). "Competitive Advantage: Creating and Sustaining Superior Performance," New York: Free Press.

Raymond, L. \& Croteau, A-M. (2009). "Manufacturing Strategy and Business Strategy in Medium-Sized Enterprises: Performance Effects of Strategic Alignment," IEEE Transactions on Engineering Management, 56( 2). 192-202. 
Reich, B. H. \& Benbasat, I. (2000). "Factors that Influence the Social Dimensions of Alignment Between Business and Information Technology Objectives," MIS Quarterly, 24(1). 81-113.

Rockart, J. F., Earl, M. J. \& Ross, J. W. (1996). "Eight Imperatives for the New IT Organization," Sloan Management Review, 38(1). 43-55.

Sabherwal, R. \& Kirs, P. (1994). "The Alignment between Organizational Critical Success Factors and Information Technology Capability in Academic Institutions," Decision Sciences, 25(2). 301-330.

Shannak, R., Masa'deh , R., Obeidat, B. \& Almajali, A. (2010). "Information Technology Investments: A Literature Review," Proceeding of the 14th IBIMA conference on Innovation and Knowledge Management in Business : An Academic Perspective ,1356 1368.

Solow, R. S. (1987). We'd Better Watch out, New York Times, Book Review.

Strassmann, P. (1990). "A Line an Included in, and Responds to Nicholas Carr Article in Harvard Business Review: IT Doesn'T Matter," Letter to the Editor: Harvard Business Review, May.
Tallon, P. P., Kraemer, K. L. \& Gurbaxani, V. (2000). "Executives' Perceptions of the Business Value of Information Technology: A Process-oriented Approach," Journal of Management Information Systems, 16(4). 145-173.

Van Dyke, T. P., Kappelman, L. A. \& Prybutok, V. R. (1997). "Measuring Information Systems Service Quality: Concerns on the Use of the SERVQUAL Questionnaire," MIS Quarterly, 21(2). 195-208.

Vitale, M. R., Ives, B. \& Beath, C. (1986). "Linking Information Technology and Corporate Strategy: An Organizational View," Proceedings of the 7th International on Information Systems, 265-276, San Diego.

Von Simson, E. (1990). "The Centrally Decentralized IS Organization," Harvard Business Review, 68, 4, 158-162.

Ward, J., Griffiths, P., (1996). "Strategic Planning For Information Systems," Wiley, New York.

Ward, J. \& Peppard, J. (1996). "Reconciling the IT/Business Relationship: A Troubled Marriage in Need of Guidance," The Journal of Strategic Information Systems, 5(1). 37-65. 


\section{APPENDICES:}

Table 1.Measurement Model Fit Indices

\begin{tabular}{|c|c|c|c|c|c|c|c|c|}
\hline Model & $\mathbf{x}^{2}$ & $\mathbf{d f}$ & $\mathbf{P}$ & $\mathbf{x}^{\mathbf{2}} / \mathbf{d f}$ & $\mathbf{I F I}$ & $\mathbf{T L I}$ & $\mathbf{C F I}$ & RMSEA \\
\hline $\begin{array}{c}\text { Initial } \\
\text { Estimation }\end{array}$ & 2548.191 & 874 & 0.00 & 2.91 & 0.71 & 0.68 & 0.71 & 0.106 \\
\hline $\begin{array}{c}\text { Final } \\
\text { Model }\end{array}$ & 884.181 & 335 & 0.00 & 2.63 & 0.81 & 0.80 & 0.81 & 0.08 \\
\hline
\end{tabular}

Table 2.Summary of Proposed Results for the Theoretical Model

\begin{tabular}{|l|c|c|c|c|}
\hline \multicolumn{1}{|c|}{ Research Proposed Paths } & $\begin{array}{c}\text { Coefficient } \\
\text { Value } \\
\text { (Std.estim) }\end{array}$ & $\begin{array}{c}\text { t- } \\
\text { value } \\
\text { (C.R) }\end{array}$ & $\begin{array}{c}\text { p- } \\
\text { value }\end{array}$ & $\begin{array}{c}\text { Empirical } \\
\text { Evidence }\end{array}$ \\
\hline $\begin{array}{l}\text { P1: Leadership } \rightarrow \text { Strategic } \\
\text { Alignment }\end{array}$ & 0.114 & 2.312 & 0.041 & Supported \\
\hline $\begin{array}{l}\text { P2: Structure and Process } \rightarrow \\
\text { Strategic Alignment }\end{array}$ & 0.011 & 0.144 & 0.885 & Not Supported \\
\hline $\begin{array}{l}\text { P3: Service Quality } \rightarrow \text { Strategic } \\
\text { Alignment }\end{array}$ & 0.100 & 2.420 & 0.036 & Supported \\
\hline $\begin{array}{l}\text { P4: Value and Belief } \rightarrow \text { Strategic } \\
\text { Alignment }\end{array}$ & 0.206 & 2.705 & 0.007 & Supported \\
\hline $\begin{array}{l}\text { P5: IT Managerial Resource } \rightarrow \\
\text { Strategic Alignment }\end{array}$ & 0.141 & 2.411 & 0.016 & Supported \\
\hline $\begin{array}{l}\text { P6: IT Implementation Success } \rightarrow \\
\text { Strategic Alignment }\end{array}$ & 0.513 & 7.446 & $* * *$ & Supported \\
\hline $\begin{array}{l}\text { P7: Strategic alignment } \rightarrow \\
\text { Sustainable competitive advantage }\end{array}$ & .316 & 4.779 & $* * *$ & Supported \\
\hline
\end{tabular}

$* * * \mathrm{P} \leq .005$ 